\title{
USO DE ENXERTO BIPEDICULADO COMO ALTERNATIVA PARA CORREÇÃO DE EXPOSIÇÃO DE PLACA ÓSSEA EM CÃO
}

(Use of bipediculated graft as an alternative for correction of exposure of bone plate in dog)

\section{Beatriz Furlan Paz*, Flávia Resende Martins da Costa, Júlia Tomazela, Aracelle Elisane Alves, Francisco Cláudio Dantas Mota}

Universidade Federal de Uberlândia, Uberlândia, MG, Brasil

*Autor para correspondência: beatrizfpaz@hotmail.com

RESUMO - Os enxertos bipediculados são empregados na medicina veterinária como uma das opções à prática de cirurgia reconstrutiva, principalmente em regiões distais de membros, onde a cooptação da ferida é mais difícil. O presente estudo tem como objetivo relatar o uso de enxerto bipediculado para o fechamento de uma lesão cutânea com exposição de implante ósseo, em membro torácico de cão. Um canino, fêmea, pinscher, com 10 meses de idade, $3 \mathrm{~kg}$, foi atendida com fratura bilateral em rádio-ulna. Foi realizada osteossíntese de ambas as fraturas. Cerca de 45 dias após redução da fratura, houve exposição de placa óssea em região cárpica de membro torácico direito (MTD). Para fechamento da lesão, confeccionou-se um retalho de plexo subdérmico direto distante bipediculado, sendo a exérese dos pedículos realizada após 10 dias da confecção do retalho. Após 30 dias foi observada completa adesão do enxerto. Devido exposição de placa óssea, o fechamento da lesão ocorreu de forma imediata, sem etapa de desbridamento para granular a ferida. A técnica empregada foi efetiva e não apresentou complicações, obtendo-se o completo fechamento da lesão. A realização de cirurgias reconstrutivas mostra-se como uma alternativa para a resolução de complicações ortopédicas em pequenos animais.

Palavras-chave: Canino; cirurgia reconstrutiva; exposição de implante.

ABSTRACT - Bipedicled grafts are used in veterinary medicine as one of the options for the practice of reconstructive surgery, especially in distal limb regions, where wound cooptation is more difficult. The present study aims to report the use of bipedicled graft for the closure of a skin lesion with exposure of a bone implant in a dog's thoracic limb. A canine, female, pinscher, 10 months old, $3 \mathrm{~kg}$, was seen with bilateral radio-ulna fracture. Osteosynthesis of both fractures was performed. Approximately 45 days after fracture reduction, bone plaque was exposed in the carpal region of the right thoracic 
limb (RA). To close the lesion, a bipedicled direct subdermal plexus flap was made, and the pedicles were excised 10 days after the flap was made. After 30 days, complete graft adhesion was observed. Due to the exposure of the bone plate, the lesion closed immediately, without debridement to granulate the wound. The technique used was effective and presented no complications, resulting in complete closure of the lesion. Reconstructive surgery is an alternative for the resolution of orthopedic complications in small animals.

Keywords - Canine; implant exposure; reconstructive surgery.

\section{INTRODUÇÃO}

As cirurgias plásticas e reconstrutivas têm sido utilizadas na medicina veterinária para a reconstrução tecidual quando não é possível o fechamento de defeitos de forma primária, sobretudo devido ao excesso de tensão presente no tecido, em defeitos e malformações congênitas ou adquiridas (Pavletic, 2007; Scheffer et al., 2013). Variados trabalhos relatam a realização de técnicas cirúrgicas reconstrutivas após exérese de tumores ou para oclusão de feridas (Tong, Simpson, 2012; Scheffer et al., 2013; Huppes et al., 2013; Fossum, 2014; Colombo et al., 2016). No entanto, foram encontrados relatos da utilização de cirurgias plásticas reconstrutivas na resolução de complicações ortopédicas apenas em tratamentos em seres humanos (Vélez-de Lachica et al., 2015), não sendo encontrados relatos na medicina veterinária.

São várias as técnicas de cirurgia reconstrutiva, como os enxertos e retalhos cutâneos, suturas para alívio de tensão ou incisões de relaxamento (Scheffer et al., 2013), sendo necessário um preparo cirúrgico adequado a fim de evitar complicações (Fossum, 2014). Retalhos locais podem sobreviver em regiões avasculares, enquanto enxertos distantes necessitam de um leito vascular próprio, como tecido de granulação. Os enxertos pediculados constituem áreas de epiderme e derme que são parcialmente destacados da área doadora para cobrir defeitos. O pedículo ou base do retalho é essencial para a manutenção sanguínea e sobrevivência do enxerto (Pavletic, 2007).

Defeitos em extremidades de membros normalmente requererem a mobilização tecidual de outra região (Tong e Simpson, 2012). Dentre as técnicas que podem ser empregadas estão os enxertos bipediculados. Estes são confeccionados por meio das etapas de desbridamento e granulação do leito receptor, criação do retalho e cicatrização; e por último, a liberação dos pedículos (Fossum, 2014).

Em ortopedia veterinária, a exposição de placas ósseas é uma complicação comumente relatada. A cobertura adequada de tecidos moles sobre placas e parafusos é 
essencial para melhor cicatrização cirúrgica, pois previne infecções, deiscência e abertura de soluções de continuidade (Boudrieau, 2012; Macedo e Moens, 2018). Fraturas radiais e ulnares distais são comuns em cães de raça miniatura e frequentemente recebem como tratamento de escolha a redução aberta. Nestes casos são relatadas alta taxa de complicações, como risco de atraso na união ou não união devido à má vascularização intraóssea, e à reduzida cobertura perióssea pelos tecidos moles, comparativamente a cães maiores (Piras, 2011; Gibert et al., 2015; Aikawa, 2018).

O objetivo deste estudo foi relatar a realização de um enxerto bipediculado como tratamento de lesão cutânea com exposição de placa óssea, proveniente da osteossíntese distal em fratura de rádio e ulna de um cão.

\section{DESCRIÇÃO DO CASO}

Uma cadela Pinscher, com massa corporal de $3 \mathrm{~kg}$ e 10 meses de idade foi atendida no Hospital Veterinário da Universidade Federal de Uberlândia (UFU), com histórico de trauma após queda. Durante o exame físico e posterior exame radiográfico identificou-se fratura bilateral distal de rádio e ulna.

Para a redução das fraturas optou-se pela artrodese com placa nos dois membros afetados. Cerca de 45 dias após a osteossíntese de ambas as fraturas, houve exposição do implante utilizado no membro torácico direito (Figura $1 \mathrm{~A}$ ), sendo indicado o emprego de técnica reconstrutiva com enxerto direto de retalho bipediculado distante para o tratamento da referida lesão.

Para esta técnica, o preparo do animal foi realizado com jejum de 6 horas para alimentação sólida e de 4 horas para líquidos. Foi utilizada como medicação préanestésica (MPA) meperidina, na dose de $5 \mathrm{mg} / \mathrm{kg}$ pela via intramuscular (IM). Após 15 minutos foi feita a indução anestésica com propofol na dose de $3 \mathrm{mg} / \mathrm{kg}$, por via intravenosa (IV), seguida por intubação orotraqueal. A manutenção anestésica foi realizada com isofluorano vaporizado em oxigênio, com volume corrente de 100 $\mathrm{ml} / \mathrm{kg} / \mathrm{min}$, em circuito semi-fechado. Para terapêutica profilática antimicrobiana administrou-se ceftriaxona na dose de $30 \mathrm{mg} / \mathrm{kg}$ IV.

O animal foi posicionado em decúbito lateral esquerdo para tricotomia (região escápulo umeral até região interdigital do membro torácico direito, lateral direita do tórax e abdome) e antissepsia (solução de clorexidine degermante e alcóolica para pele e de clorexidine degermante para a ferida na região cárpica). Os dígitos foram envolvidos em uma compressa estéril a fim de evitar contaminação do foco cirúrgico e do leito doador do enxerto durante o posicionamento do leito receptor. 
Para a confecção do enxerto, fez-se a aproximação do membro à região toracoabdominal direita para delimitar a área doadora, adicionando um $\mathrm{cm}$ à largura do pedículo, em relação à largura do defeito e dois centímetros a cada incisão, para que a passagem do membro pelo túnel fosse facilitada. Após a definição de suas dimensões, o retalho foi confeccionado a partir de incisão de pele com bisturi e divulsão sob o músculo cutâneo (Figura 1 B).

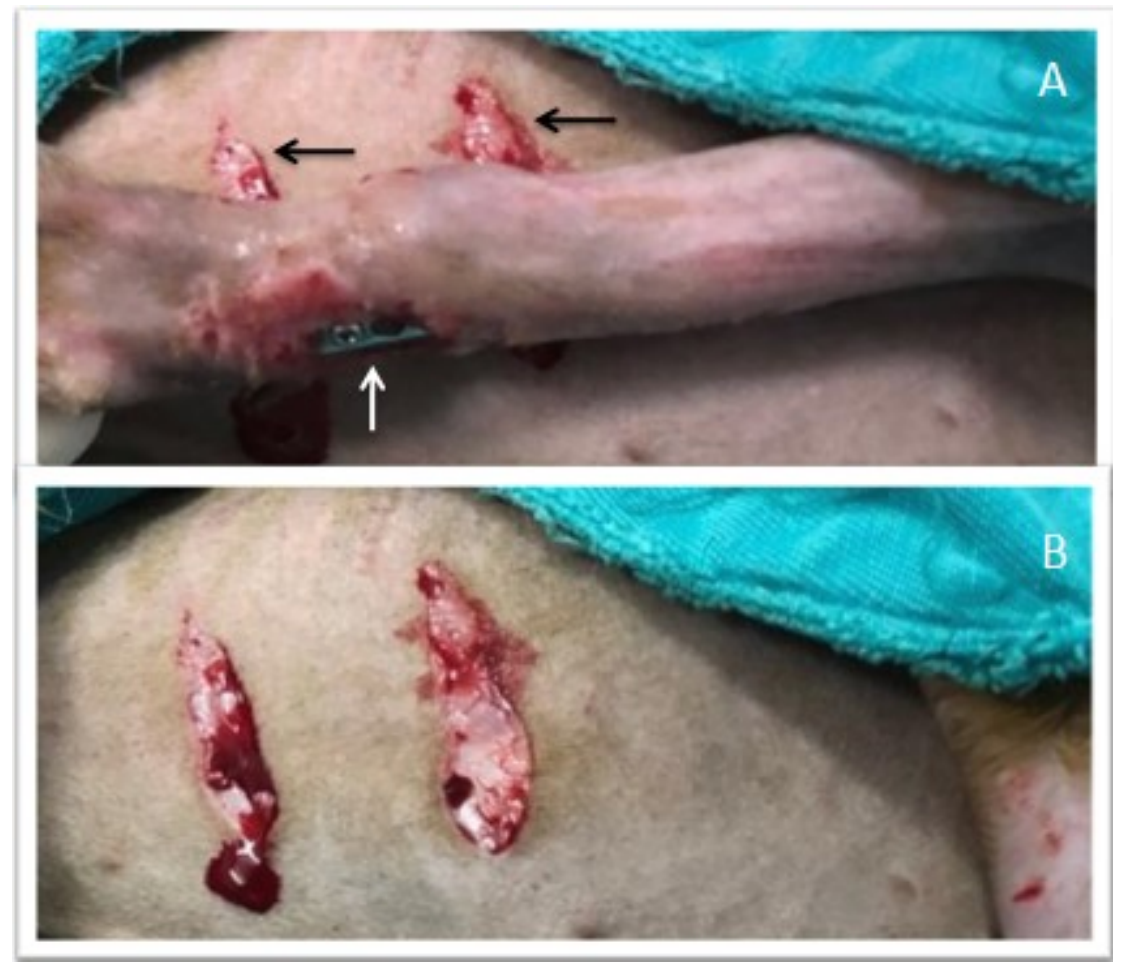

Figura 1- A) Lesão cutânea com exposição de placa de aço inoxidável (seta branca) em membro torácico de cão e área de incisão de pele para confecção do retalho (setas pretas). B) Incisões cutâneas para confecção do flape.

O membro foi posicionado no interior do retalho, acomodando a região da ferida no local doador (Figura 2) e a pele foi suturada com pontos simples separados e fio nylon 3.0. Foi realizado curativo acolchoado imobilizando o membro na lateral toracoabdominal do animal, com trocas diárias. 

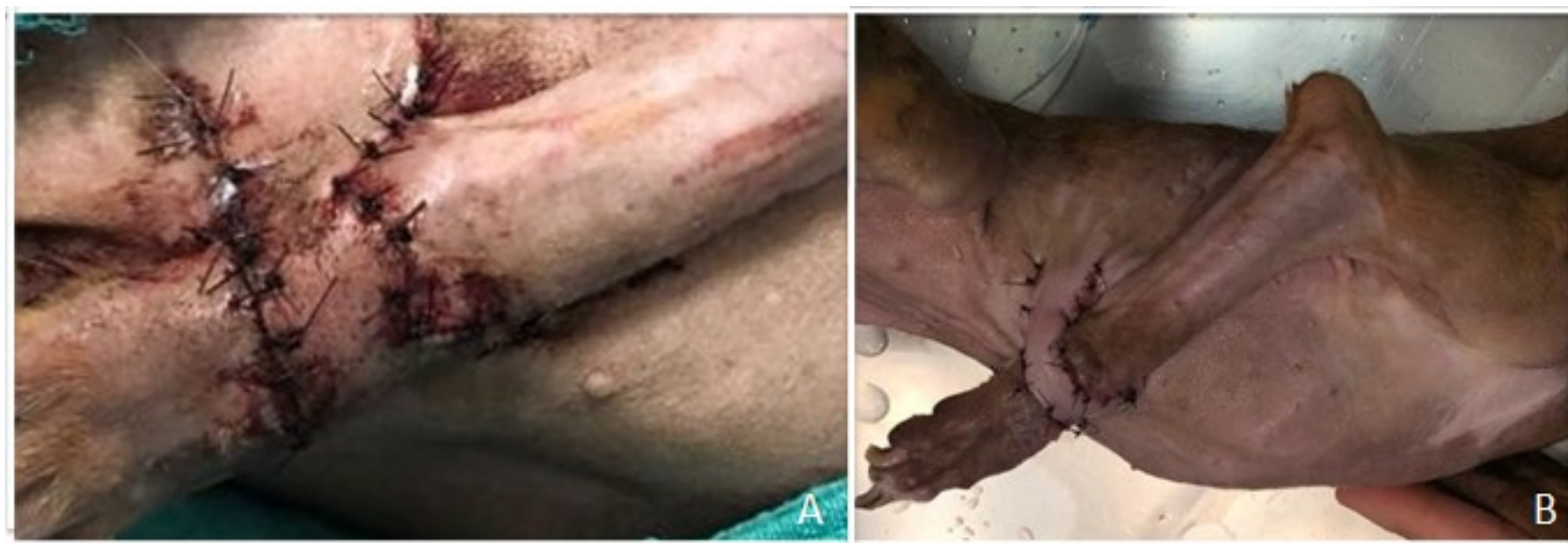

Figura 2 - A e B) Membro posicionado no interior do enxerto em bolsa, com região da ferida acomodada sob a região doadora.

Após 10 dias de pós-operatório foi realizada a incisão nos pedículos do flape, já integrado ao leito receptor, liberando o membro torácico (Figura $3 \mathrm{~A}$ ). A pele da área doadora e receptora foi suturada com pontos simples separados e fio nylon 3.0, sendo realizada sutura em $Y$ na área doadora. Como complicação observou-se apenas edema de borda cutânea no pós-operatório imediato à sutura da pele doadora à receptora, o qual não foi observado durante o curativo realizado no dia seguinte ao procedimento e tampouco se repetiu em qualquer outro momento do acompanhamento da paciente.

A remodelação gradativa do enxerto foi acompanhada ao longo de 30 dias, sem complicações (Figura 3 B).

Não ocorreram complicações relativas à osteossíntese, com preservação da forma e função do membro. Aos 45 dias pós-operatórios a paciente apresentou completa recuperação da lesão (Figura 4), apesar da diferença de textura da pele enxertada em contraste com a área receptora, visto tratar-se de um retalho de pele da região toracoabdominal, mais delgada e menos pilosa que a do membro torácico. 


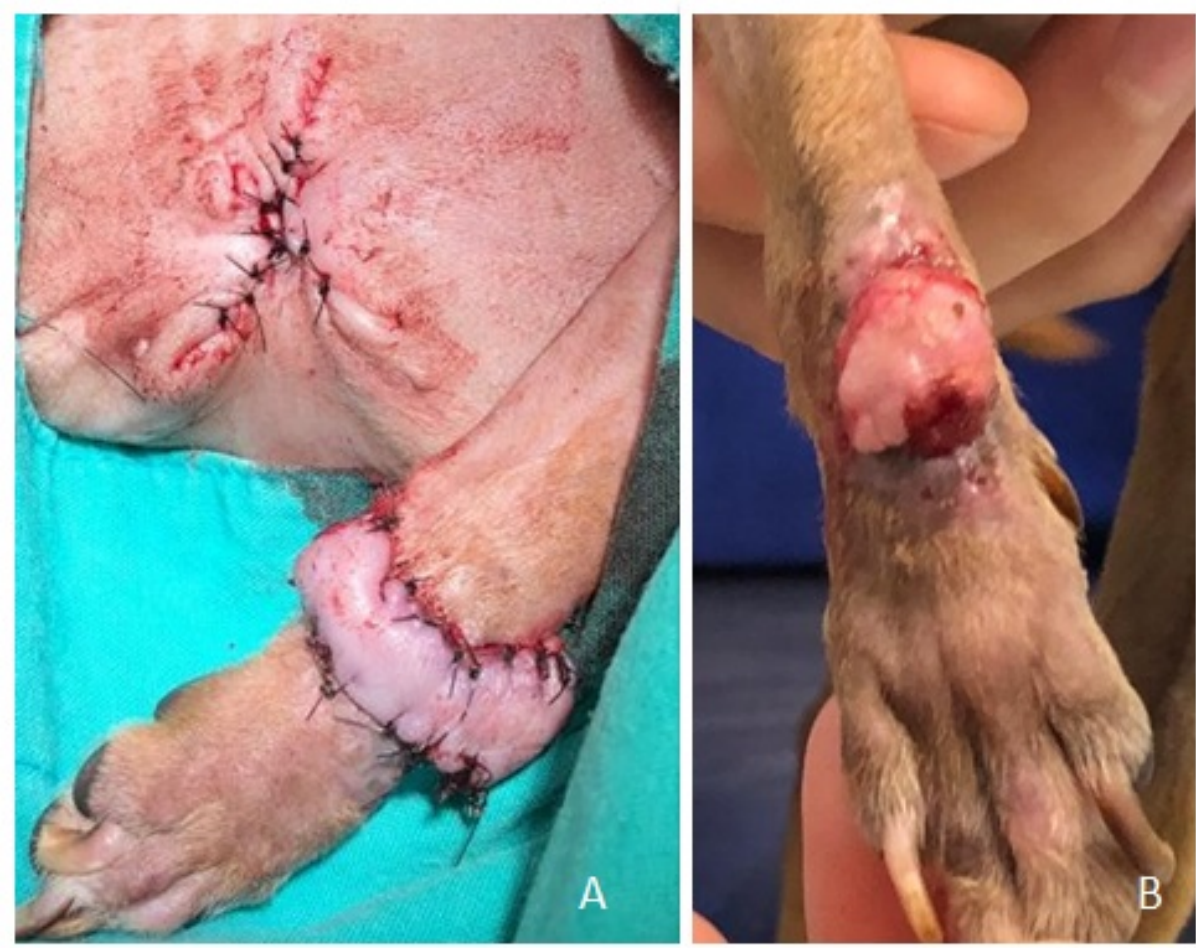

Figura 3 - A) Após 10 dias de pós-operatório foi realizada a liberação do membro do interior do retalho. B) Após 30 dias, aspecto da área receptora do retalho em remodelação.
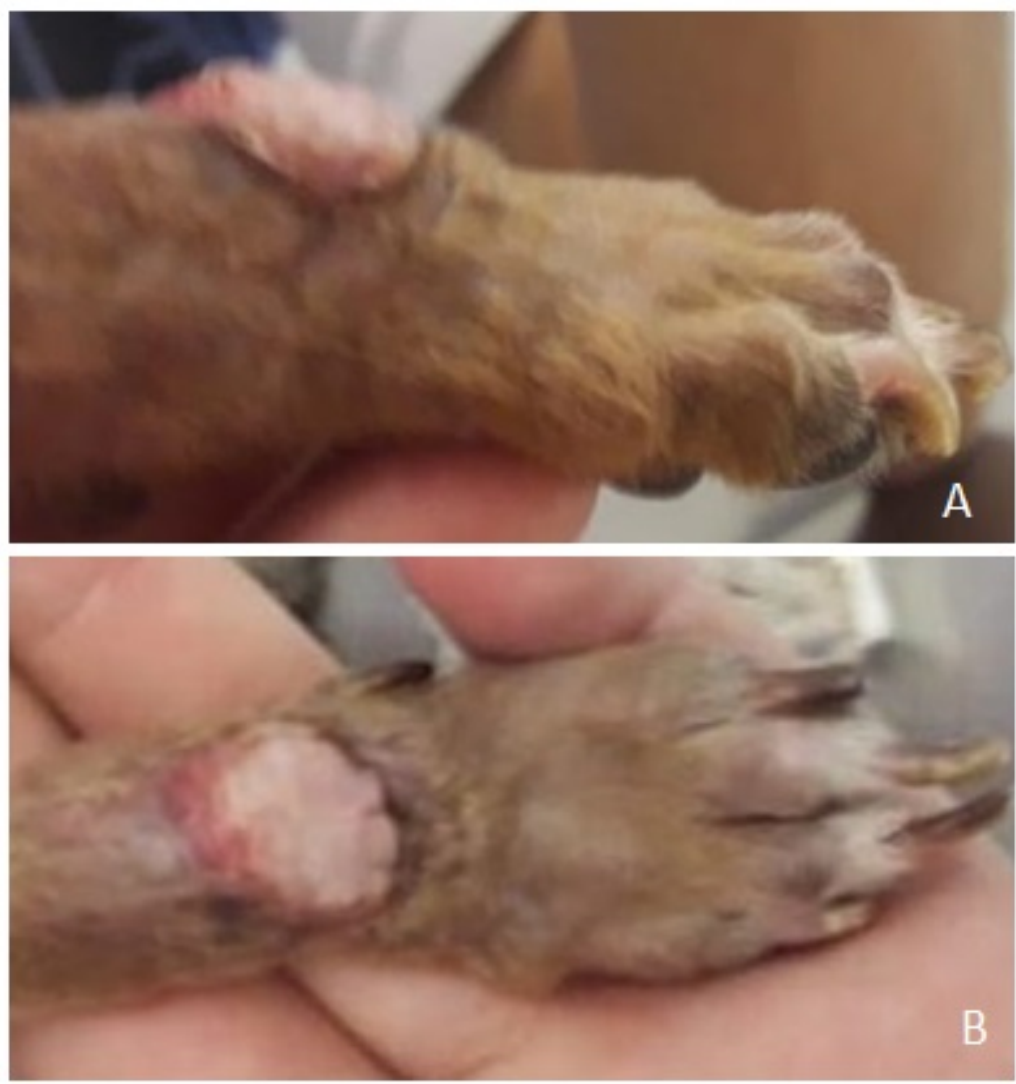

Figura 4 - A e B) Aspecto da área receptora do retalho após 45 dias de sua confecção. 


\section{DISCUSSÃO}

No planejamento da cirurgia reconstrutiva, o local da ferida, a elasticidade dos tecidos circunvizinhos, o suprimento de sangue regional e o caráter do leito da ferida devem sempre ser avaliados (Nardi et al., 2016). No presente relato, o animal apresentava exposição de uma placa de aço inoxidável em região cárpica, região que apresenta maior dificuldade em ser ocluída com retalhos locais, devido a reduzida elasticidade do tecido (Faria et al., 1986).

Há diferentes possibilidades de técnicas reconstrutivas para lesões em regiões distais de membros, com capacidade de abrangência parcial ou total do defeito, como a transferência direta ou indireta de retalhos distantes, enxertos livres e expansores teciduais (Pavletic, 2007; Tong, Simpson, 2012). Devido à necessidade imediata de cobertura tecidual e ausência de vascularização no leito receptor, optou-se pela realização do retalho distante direto bipediculado, que apresenta dupla fonte de irrigação ao enxerto, favorecendo o aporte sanguíneo do retalho, e chances de êxito do procedimento (Pavletic, 2007). Para esta técnica, a região toracoabdominal, ipsilateral à lesão, é frequentemente utilizada como doadora (Fossum, 2014), como foi no presente relato, devido à proximidade ao membro afetado e o conforto da paciente.

O sucesso da integração de um enxerto cutâneo depende do processo de vascularização do leito da lesão, pelo estabelecimento de irrigação arterial e drenagem (Agostini et al., 2018). Um grande desafio enfrentado para a sobrevivência do enxerto cutâneo foi a ausência de uma circulação primária após excisão do pedículo ou a ausência de tecido vascularizado presente no leito da ferida.

Pavletic (2007), relatou que, os retalhos, de modo geral, sobrevivem devido à circulação original do tecido, já os enxertos livres, requerem a revascularização do leito receptor. Revascularização esta que foi necessária para o sucesso cicatricial do presente relato.

Feridas contaminadas frequentemente apresentam como principal indicação terapêutica cicatrização por segunda intenção. No entanto, há defeitos cuja cicatrização primária se faz necessária, como aqueles que apresentam exposição de ligamentos, tendões, vasos e nervos (DERNELL, 2006). Segundo Pavletic (2007), os enxertos pediculados destacam-se de forma valiosa para a cobertura e proteção dessas estruturas. Conforme observado no presente relato, o enxerto bipediculado pode caracterizar-se como uma técnica alternativa para a resolução de complicações ortopédicas que necessitem de cicatrização primária, como a exposição de placa óssea.

A técnica descrita no presente relato apresenta como particularidade o fato de ser composta por mais de um estágio (Fossum, 2014). O enxerto bipediculado apresenta 
maiores chances de sucesso quando há controle de infecção e presença de tecido saudável com tecido de granulação exuberante no leito receptor (Pavletic, 2007; ReisFilho et al., 2017). Para iniciar o segundo estágio, que consiste na criação do retalho, indica-se a formação prévia de tecido de granulação (Reis-Filho et al., 2017), o que não foi possível diante do quadro clínico desta paciente, cuja ferida não apresentava infecção tecidual, no entanto, era necessário reparo imediato e colocação do enxerto em contato direto com a placa óssea, visando prevenir osteomielite e outras complicações.

No trabalho de Huppes et al. (2013), para a confecção de flape bipediculado, foi realizado inicialmente procedimento cirúrgico de desbridamento e tratamento tópico de lesão cutânea, em extensão completa de rádio e ulna de um cão, cuja causa estava relacionada a acidente automobilístico ocorrido há mais de 10 dias. Após desbridamento, aguardou-se 15 dias para a realização do retalho. Neste trabalho, o primeiro e segundo estágio foram realizados de forma conjunta em um procedimento. A necessidade de formação de tecido de granulação no trabalho de Huppes et al. (2013) pode ter ocorrido por tratar-se de uma ferida crônica, que não apresentava exposição óssea e necessidade de cicatrização primária, como observado no presente trabalho.

O efeito estético do enxerto bipediculado nem sempre corresponde às expectativas, pois este pode apresentar coloração e padrão de crescimento de pelo diferente da região receptora (Pavletic et al., 2007). Quando possível, o cirurgião deve se atentar para a direção de crescimento e coloração dos pelos durante a seleção da região doadora para a confecção do retalho (Faria et al., 1986). Devido período restrito de acompanhamento do animal, não foi possível avaliar as características de coloração e crescimento de pelos após completa cicatrização.

Para execução da técnica relatada, o membro do animal é posicionado na face lateral de seu corpo (Huppes et al., 2013). Alguns animais podem não tolerar a imobilidade do membro, pois além de apresentarem incômodo devido à imobilização da região afetada, pode ocorrer rigidez temporária e atrofia muscular (Faria et al., 1986; Fossum 2014). No pós-operatório, as ataduras aplicadas sobre a sutura podem servir para absorver fluidos, sustentar a incisão, comprimir o espaço morto e evitar traumatismo ou contaminação, além de melhorem o conforto do paciente por sustentarem o membro e ferimento, evitando complicações (Faria et al., 1986; Colombo et al., 2016). Não ocorreram atrofia muscular ou rigidez nas articulações do membro utilizado para a técnica descrita neste relato, sendo observada funcionalidade preservada para deambulação. 
Há estudos que avaliaram o melhor período para manutenção da bolsa de sutura, prévia a liberação do flape, sendo 8 ou 14 dias (Steven e Phillip, 1981; Faria et al, 1986). Um relato encontrado descreveu o emprego de até 21 dias (Huppes, 2013). Fossum (2014) descreve a necessidade de aguardar 14 dias para a retirada do pedículo, visando menor risco de necrose. No entanto, foi necessária a retirada do membro do animal em 10 dias devido ao comportamento da cadela, que passou a mostrar-se mais agitada e incomodada com o posicionamento do membro. De acordo com a literatura, períodos menores de manutenção do retalho bipediculado também são eficazes para a confecção do flape (Faria et al, 1986).

No presente estudo, a fixação do enxerto apresentou resultado satisfatório para liberação em 10 dias de pós-operatório. Faria et al. (1986), observaram melhor resultado no grupo experimental, composto por cadelas cuja liberação do enxerto utilizado para reconstituição de pele em feridas produzidas em região lateral do membro torácico foi realizada em menor período, com apenas 8 dias. A confecção do retalho no trabalho de Faria e colaboradores (1986), foi realizada imediatamente após a incisão de ferida cutânea, portanto, sem formação de tecido de granulação no leito receptor. A maior permanência do leito receptor no interior da bolsa foi relacionada a formação de tecido cicatricial exuberante (Faria et al., 1986), observado no presente relato, cuja manutenção do flape foi de apenas 10 dias.

Deve-se levar em consideração os perfis dos pacientes e as expectativas dos respectivos tutores para a proposição de enxertos bipediculados. Animais de temperamento agitado ou agressivo, com sobrepeso, de maior porte ou portadores de doenças articulares não são considerados bons candidatos para a técnica supracitada (Slatter, 2007). Apesar do comportamento da presente cadela ter sido avaliado previamente e ser indicada a confecção do flape bipediculado para a paciente, percebeuse que o período extenso de 14 dias para manutenção do membro na bolsa cutânea não era necessário para a fixação do flape, sendo um período de maior estresse também ao animal.

As principais complicações observadas em cirurgias reconstrutivas envolvem deiscência de sutura, contaminação, necrose da extremidade dos retalhos, seroma, hemorragias e hematomas. Neste estudo, observou-se presença de edema em borda cutânea apenas no pós-operatório imediato, não sendo observado no dia seguinte ao procedimento e tampouco se repetiu em qualquer outro momento do acompanhamento da paciente. O edema supracitado é referido como uma possível ocorrência descrita em literatura (Nardi et al. 2016). 


\section{CONCLUSÃO}

O uso do enxerto bipediculado para reconstituição de lesão cutânea em região distal de membro torácico na espécie canina, mesmo quando desprovida de tecido de granulação, mostrou-se como uma alternativa viável para o tratamento de complicações ortopédicas decorrentes da exposição de implante, apresentando resultados satisfatórios em relação à cicatrização, estética e funcionalidade do membro.

\section{REFERÊNCIAS}

AGOSTINI, S. A.; SILVA, E. M.; VARALLO, G. R. Princípios da enxertia cutânea em cães. Revista Científica de Medicina Veterinária-UNORP, v.2, n.1, p. 21-33, 2018.

AIKAWA, Takeshi et al. Clinical outcomes and complications after open reduction and internal fixation utilizing conventional plates in 65 distal radial and ulnar fractures of miniature-and toy-breed dogs. Veterinary and Comparative Orthopaedics and Traumatology, v. 31, n. 3, p. 214-217, 2018.

BOUDRIEAU, R.J. Maxillofacial fractures repair using miniplates and screws. In: VERSTRAETE, F.J.M.; LOMMER, M.J. Oral and maxillofacial surgery in dogs and cats. Toronto: Saunders Elsevier, 2012. p. 293-308.

COLOMBO, B. B.; KUCl, C. C.; GEHRCKE, M. I. et al. Reconstrução cirúrgica com retalho pediculado de avanço após exérese de melanoma cutâneo facial em um cão-Relato de caso. Brazilian Journal of Veterinary Medicine, v. 38, n. 2, p. 128-132, 2016.

DERNELL, W. S. Initial Wound Management. Veterinary Clinical Small Animal. v. 36, n. 4 p. 713-738, 2006.

FARIA, M. A. R., PIPPI, N. L., MORAIS, A. N. et al. Reconstituição de ferida de pele no membro anterior de cão usando flape bipediculado. Revista Centro de Ciências Rurais, v. 18, n, 1, p. 29-31, 1986.

FOSSUM, T. W. Cirurgia de Pequenos Animais. 4 ed. Rio de Janeiro: Elsevier, 2014. 1619 p. GIBERT, S., RAGETLY, G.R., BOUDRIEAU, R. J. Locking compression plate stabilization of 20 distal radial and ulnar fractures in toy and miniature breed dogs. Veterinary and Comparative Orthopaedics and Traumatology, v. 28, n.6, p. 441-447, 2015.

HUPPES, R. R., ZANELLA, J. C., NARDI, A. B. et al. Flape bipediculado no tratamento de lesão cutânea em membro torácico de cão - relato de caso. Jornal Brasileiro de Cirurgia Veterinária, v. 2, n. 2, p. 98-101, 2013.

MACEDO, A.S.; MOENS, N.M.M. Zygomatic arch fracture in a dog treated with Veterinary Cuttable Plate - case report. Arquivo Brasileiro de Medicina Veterinária e Zootecnia, v. 70, n. 3, p. 675-681, 2018. 
NARDI, A. B.D.; PAZZINI, J. M.; CASTRO, J. L.; et al. 2016. Complicações em cirurgias reconstrutivas de pele. In: CASTRO, J. L. C.; HUPPES RR, NARDI ABD, PAZZINI, J.M., Princípios e técnicas de cirurgias reconstrutivas da pele de cães e gatos. 1 ed. Curitiba: Medvep, 2016, pp. 201-204.

PAVLETIC, M.M. Enxertos Pediculados. In: SLATTER, D. Manual de cirurgia de pequenos animais. 3 ed. Barueri, SP: Manole, 2007, cap. 23, p .292 - 238.

PIRAS, L.; CAPPELLARI, F.; PEIRONE, B. et al. Treatment of fractures of the distal radius and ulna in toy breed dogs with circular external skeletal fixation: a retrospective study. Veterinary and Comparative Orthopaedics and Traumatology v. 24, n.3, p. 228-235, 2011.

REIS FILHO, N.; FERREIRA, M.; PASCOLI, A.; et al. Epitelização de enxertos cutâneos em feridas recentes de coelhos tratados com membrana amniótica canina e/ou laserterapia. Arquivo Brasileiro de Medicina Veterinária e Zootecnia, v. 69, n. 3, p. 603-612, 2017.

SCHEFFER, J.P.; ATALLAH, F. A.; GOMES, C., et al. Cirurgia reconstrutiva no tratamento de feridas traumáticas em pequenos animais. Brazilian Journal of Veterinary Medicine, $v$. 35, n. Supl. 1, p. 70-78, 2013.

STEVEN, J.; PHILIP, K. T. Tissue healing using polypropylene and PGA. American Journal of Veterinary Research, v. 42, p. 563-570, 1981.

TONG, T.; SIMPSON, D. J. Free skin grafts for immediate wound coverage following tumour resection from the canine distal limb. Journal of Small Animal Practice, v. 53, n 9, p. 520-525, 2012.

VÉLEZ-DE LACHICA，J. C; BRAMBILA-BOTELLO, C. A; VALDEZ-JIMÉNEZ, L. Luxación radiocubital distal expuesta por mordedura canina no asociada con fractura: Técnica quirúrgica reconstructiva mediante anclaje para sindesmosis e injerto tendinoso. Reporte de caso. Acta ortopédica mexicana; v. 29, n. 4, p. 218-222, 2015. 